\title{
Enteral Nutrition: A Health Approach
}

Veena Kumari, Jayadeep A

10.18805/ajdfr.DR-1462

\begin{abstract}
Healthy individuals consume solid food and receive nutrition by mouth through swallowing and then digesting it. However, individuals not able to obtain nutrition by swallowing can receive Enteral Nutrition or Tube Feeding. It comprises of tubal feeding to obtain the nutrients needed by the body. There is a wide range of enteral formulations available in the market, like standard polymeric, oligomeric, organ-specific, therapeutic formulas, nutrition supplements, and modules. They are also classified according to their composition, administration route, and general or special purposes utilization. These formulations must be in liquid form to obtain the same nutrients that are found in solid food. The composition of the formula generally affects the recovery of the patient.

Keywords: Complete formula, Enteral formulation, Nutrition, Standard formula.

Asian Journal Of Dairy and Food Research (2019)
\end{abstract}

\section{INTRODUCTION}

$\mathrm{T}$ oday, the importance of nutrition for the prevention and cure of diseases is well realized by populations at large. During illness, the requirement of nutrients increased to meet its demands for tissue repair. Patients need adequate nutrition to recover from illness, and critically ill patients such as patients with a head injury, burn, coma, post-surgery, etc. have higher nutritional requirements. Healthy individuals consume food through the mouth and receive nutrition by swallowing and digesting it. Sometimes a patient cannot eat by mouth because of difficulties in swallowing. In such a condition, when one is not able to eat, nutrition must be supplied differently. One such method is "enteral feeding" or "tube feeding."

\section{Enteral Nutrition}

The term enteral route means "within or by way of the gastrointestinal (GI) tract." In other words, feeding by the gastrointestinal tract is called "enteral feeding." It is a means of supporting the patient's nutrient requirement through the alimentary tract, which is not able to meet nutritional requirements by the oral route to maintain and restore nutritional status (Boullata et al., 2017). In commercially available nutritional supplements, "enteral feeding" and "tube feeding" are used interchangeably.

\section{The need for Enteral Nutrition}

Enteral feeding is given to the patients, who are not able to feed themselves orally. Patients may require such feeding for a wide range of underlying conditions. These conditions could be a physical obstruction to swallow, unable to ingest food due to head injury or stroke, motor neuron disease, multiple sclerosis, anorexia, chronic lung disease, irritable bowel disease, cancer, etc. The unconscious or sedated patients also require enteral feed. Patients with severe gut problems will require long terms of enteral feeding (Pearce and Duncan, 2002). It is also required for hospitalized patients and bedridden geriatric population. It is the first option when
Grain Science and Technology Department, CSIR-Central Food Technological Research Institute, Mysore, Karnataka, India

Corresponding Author: Jayadeep A, Grain Science and Technology Department, CSIR-Central Food Technological Research Institute, Mysore, Karnataka, India, Email: jayadeep@cftri.res.in

How to cite this article: V.K. and J.A. (2019). Enteral Nutrition: A Health Approach. Asian Journal Of Dairy and Food Research, 38(3): 261-264.

Source of support: Nil.

Conflict of interest: None

Submitted:09-07-2019 Accepted:17-10-2019 Published: 01-11-2019

one needs artificial nutrition, keeping parenteral nutrition only for those cases in which enteral nutrition would be insufficient or impossible (Seres et al., 2013).

\section{Nutrient Composition:}

Composition of enteral formulas is a matter of importance. A balanced diet is an ultimate requirement for good health. The formulation of enteral nutrition products composes carbohydrates, lipids, protein, vitamins, minerals, fiber, and water. The nutrient requirement needs to be modified according to the patient's needs, specific disease condition, and rate of loss (Weber and Ehrlein, 1999).

\section{Carbohydrate}

It is the chief energy source. The Carbohydrate contribution of the formula should be in the most digestible form like maltodextrins, cornstarch, glucose contributing calories in the range of 30-90\% (Savino, 2017).

\section{Lipids}

lipids provide energy in the dense form and serve as a vehicle for fat-soluble vitamins. Corn, soybean, canola, and safflower oil have greater use in the formulas and are used in the range of $1-55 \%$ essential fatty acids like linoleic acid form 3-4\% total calories. The supply of long-chain omega-3 polyunsaturated fatty acids is useful in anti-inflammatory 
and immune-modulating effects. Fat does not contribute to the osmolality of formula (Kannan, 2008). The polysaccharide carrageenan derived from red algae is used as emulsifiers and thickening agents (Hebar et al., 2015).

\section{Protein}

Quality and quantity of protein are determined based on individual differences, which can be polymeric, monomeric, or oligomeric, ranging from $4-32 \%$ of total calories (Chen, 2001).

\section{Micronutrients}

Just as macro-nutrients, micronutrients like $\mathrm{Zn}, \mathrm{Se}, \mathrm{Cu}$ and vitamins are also be included in the required quantities.

\section{Fiber}

Enteral feed mostly contains soluble fiber, which has viscous or gel-forming properties in the range of $5-15 \mathrm{~g}$ per liter. Viscous fibers are guar, glucomannans, pectins, oat betaglucan, and psyllium; nonviscous fibers are inulin, partially hydrolyzed guar gum, wheat dextrin, or acacia (Kaczmarczyk et al., 2012). Fiber and its fermented products (short-chain fatty acids) have a potential impact on intestinal health. Soy and carrot fiber, guar gum, and wheat dextrin are the most commonly added fiber in formulas. A recent fiber addition formula is fructooligosaccharides (FOS), which releases short-chain fatty acids of immense physiological values (Pan et al., 2009).

\section{Water}

Water is used as a medium for reconstitution of enteral feed. It acts as a diluent for nutrients and helps in the removal of waste from the body. The enteral formulation contains water in the wide range of $690-860 \mathrm{~mL}$ per $1000 \mathrm{~mL}$ of formula (Nilesh et al., 2011).

\section{Classification of Enteral formulas}

Enteral formulas are classified according to their composition with the complete or incomplete source of nutrients, administration route, and according to general or special purposes utilization. Each type has advantages and disadvantages. Indeed, enteral formulas can be grouped as polymeric, oligomeric, organ-specific, therapeutic, nutrition supplements, and modules right choice of the formula is critical for the best outcome (Table1).

\section{Standard or polymeric formula}

A nutritionally complete formula contains intact protein, partially hydrolyzed protein or amino acids, and fat in the form of long-chain triglycerides. Carbohydrates, protein, and fat are in complex forms. They need to be digested. Maltodextrins is the preferred form of carbohydrate. These formulas should be complete concerning vitamin, minerals, and contain fiber. The formulas are to provide $40-60 \%$ of calories from carbohydrate $12-20 \%$ from protein and $30-40 \%$ from fats. Most of the polymeric formulas is lactose-free, gluten-free, and low viscosity (Zadak and Kent-Smith, 2009).

\section{Elemental (monomeric)}

Elemental formulations are designed for patients with "limited" digestive capacity. It is advantageous in patients with acute pancreatitis and malabsorptive syndrome. This formula requires minimal digestion and causes less stimulation of exocrine pancreatic secretion with simple peptides, maltodextrins and triglycerides.

\section{Semi-elemental (polymeric)}

These formulas contain peptides of varying chain length, simple sugars such as glucose polymers or starch, and fat in the form of Medium-chain triglycerides (MCT).

\section{Modular diets}

They comprise of macronutrients alone or in combination with specific nutrients.

\section{Disease-specific formulas}

Such formulations are specific ones for different diseased condition (Fietkau et al., 2013). Disease-specific formulas are available in the market as diabetic formulas, renal formulas, hepatic formulas, pulmonary formulas, etc.

\section{Specialty diet products}

They are special formula for unique requirements, e.g. arginine for injury treatment and glutamine for skeletal breakdowns. Nucleotides are added to some formulas as immunity enhancers (Preiser et al., 2015).

\section{Blenderized Diets}

A blended diet is defined as home-made food blended to a smooth 'single cream' consistency. It consists of mixtures of several foods, usually a protein source such as meat, egg, milk, or legumes along with fruits, vegetables, starches, sugar, butter, vegetable oil, and water. The feed may be prepared in the kitchen of a hospital or at home, by combining a variety of foods and liquids in a blender or by mixing strained foods with a consistency that will flow through a feeding tube (Rastogi, 2010). These blended formulas are available commercially, where natural ingredients optimally processed and packed.

\section{Home Blend Formulas}

Home blend formulas could be prepared at home itself and could be given to the patient who required home feeding. These formulas comprise of single or multiple ingredients.

\section{Food Safety and Standards Authority of India (FSSAI) regulation related to the enteral formula}

Food for the special medical purpose shall include food specially prepared for total replacement of normal diet. A food business operator may formulate food for $s$ medical purpose in a format meant for oral feeding through enteral tubes. The article of food for the medical purpose shall not be used for parenteral use. The article of food for the special medical purpose may either be a nutritionally complete food or supplemental in nature (FSSAI, 2016). 
Table 1

\begin{tabular}{|c|c|c|c|}
\hline S.No & Product category & Product name & Image of the product \\
\hline 1. & $\begin{array}{l}\text { Standard or } \\
\text { polymeric } \\
\text { formula }\end{array}$ & $\begin{array}{l}\text { Fibersoure HN, Jevity } 1 \text { Cal, Jevity } 1.2 \text { Cal, Isosource HN, Nutren } \\
\text { 1.0, Nutren 1.0 Fiber, Osmolite } 1 \text { Cal, Osmolite } 1.2 \text { Cal, Promote, } \\
\text { Promote with fiber, Nutren replete, Nutren replete with fiber. }\end{array}$ & 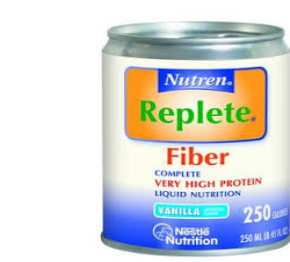 \\
\hline 2 & $\begin{array}{l}\text { Elemental and } \\
\text { Semi-elemental }\end{array}$ & $\begin{array}{l}\text { Crucial, Optimental, Peptamen, Peptamen 1.5, Vital HN, Vital 1.0Cal, } \\
\text { Vital 1.5 Cal, Vivonex plus, Vivonex RTF, Vivonex TEN, Tolerex }\end{array}$ & \\
\hline 3. & Modular diets & $\begin{array}{l}\text { Duocal, Polycose, Benecalorie, Promod, Beneprotein, MCToil } \\
\text { Microlipid, Juven, Glutamine containing products }\end{array}$ & \\
\hline 4 & $\begin{array}{l}\text { Disease specific } \\
\text { formulas }\end{array}$ & $\begin{array}{l}\text { Diabetisource AC, Glucerna, Nutren glytrol, Nepro with carb } \\
\text { steady, Novasource renal, Nutrihep, Perative, Pulmocare, Nutren } \\
\text { pulmonary, Impact, Impact 1.5, Oxepa }\end{array}$ & \\
\hline 5 & $\begin{array}{l}\text { Specialty diet } \\
\text { products }\end{array}$ & Resource Glutasolve, Resource arginaid & \\
\hline 6 & Blenderized Diets & Compleat & cúmpleat \\
\hline 7. & $\begin{array}{l}\text { Home blend } \\
\text { formula }\end{array}$ & $\begin{array}{l}\text { Meat, egg, milk or legumes, fruits, vegetables, starches, sugar, } \\
\text { butter, vegetable oil, water }\end{array}$ & \\
\hline
\end{tabular}

\section{(Source: www.google.com.in)}

\section{CONCLUSION}

Enteral feeding is used for an individual who is not able to take a sufficient amount of nutrients to meet their current needs orally. Such feeds are delivered through tubes into the alimentary tract. . They contain nutrients and phytochemicals to improve immunity. Selection of ingredients is critical in enteral feeding.

\section{ACKnOWLedgment}

Authors acknowledge Council of Scientific and Industrial Research (CSIR)-Central Food Technological Research Institute,
Mysore, India for the facilities provided and University Grant Commission for providing fellowship to Veena Kumari.

\section{References}

Alexander, D.D., Bylsma, C., Elkayam, L., Nguyen, L.D. (2016). Nutritional and health benefits of semi-elemental diets: $A$ comprehensive summary of the literature. World Journal of Gastrointestinal Pharmacology and therapeutics. 7(2): 306-319.

Bell, S.J., Bistrian, B.R., Wade, J.E. and Blackburn, G.L. (1987). Modular enteral diets: cost and nutritional value comparisons. Journal of the American Dietetic Assocociation: 87(11). 1526-1530. 
Boullata, J.J., Carrera, L.A., Harvey, L., Escure, A.A., Hudson, L., Mays, A., McGinnis, C., Wessel, J.J., Bajpai, S., Beebe, L.M., Kinn, J.T., Klang, G.M., Lord, L., Martin, K., Wolfe, P.C., Sullivan, J., Wood, A. and Malone, A. (2017). ASPEN Safe practices for enteral nutrition therapy. Journal of Parenteral and Enteral Nutrition. 41: 15-103

Chen, Q.P. (2001). Enteral Nutrition and acute pancreatitis. (2001). World Journal of Gastroenterology. 7(2). 182-192.

Dao, T.D., Bustillos, A.L., Cho, S.B., Li, Z., Puder, M. and Gura, M.K. (2017). Assessment of micronutrient status in critically ill children: challenges and opportunities. Nutrients. 9(11): 1-26.

Farrell, J.J. (2010). Digestion and absorption of nutrients and Vitamins. In: Feldman, M., Friedman, L.S., Sleisenger, M.H, Eds sleisenger and Fordtran's gastrointestinal and liver disease: pathophysiology, diagnosis, management. $9^{\text {th }}$ ed. Philadelphia, p.1695.

Fietkau, R., Lewitzki, V., Kuhnt, T., Holscher, T., Hess, C.F., Weigel, T., Rodel, C., Niewald, M., Hermann, R.M. and Lubgan, D.A. (2013). Disease-specific: enteral nutrition formula improves nutritional status and functional performance in patients with head and neck and esophageal cancer undergoing chemoradiotherapy: results of a randomized, controlled, multicancer trial. Cancer: 119(18): 3343-53

Fssai:https://www.fssai.gov.in/.../Direction-Nov 24, 2016

Hebar, A., Koller, C., Seifert, M.J., Chabicovsky, M., Bodenteich, A., Schnurch, B.A. and Grassauer, P.E. (2015). Non-clinical safety evaluation of intranasal lota-carrageenan. Plos ONE. 10(4): 1-16.

Kachmarczyk, M.M., Miller, J.M. and Freund, G.G. (2012). The health benefit of dietary fiber: beyond the suspects of type 2 diabetes, cardiovascular disease and colon cancer. Metabolism. 61(8): 1058-1066.

Kannan, M. (2008). Nutrition in critically ill patients. Indian Journal of Anaesthesia. Suppl.52 (5): 642-651.

Nilesh, R.M., Vilas, A.P., Ambadas, S.J., Nilesh, M. (2011). Formulation development of enteral nutrition products. International Research Journal of Pharmacy. 2(3): 19-28.
Pan, D.X., Chen, Q.F., Wu, T., Tang, G.H. and Zhao, Y.Z. (2009). Prebiotic oligosaccharides change the concentration of short chain fatty acids and the microbial population of mouse bowel. Journal of Zhejiang University Science B. 10(4). 2 58-263.

Pearce, B.C. and Duncun, D.H. (2002). Enteral feeding. Nasogastric, nasojejunal, percutaneous endoscopic gastrostomy or jejunostomy: its indication and limitation. Postgraduate Medicine: 78(918): 198-204.

Preiser, C.J., Zanten, A., Mette, M.B., Biolo, G., Casaer, P.M., Doig, S.G., Griffiths, D.R., Heyland, K.D., Hiesmayr, M., Lapichino, G., Laviano, A., Pichard, C., Singer, P., Berghe, D.V.G., Wernerman, J., Wischmeyer, P. and Vincent, L. (2015). Metabolic and nutritional support of critically ill patients: consensus and controversies. Critical care. 19(1). 35.

Rastogi, S. (2010). Eat right to stay bright- Manage diet to manage disease, Kindle edition. Popular Prakashan. PVT.LTD.

Savino, P. (2018). Knowledge of constituent ingredients in enteral nutrition formulas can make a difference in patient response to enteral feeding. Nutrition in clinical Practice. 33(1):90-98.

Seres, S.D., Valcarcel, M. and Guillaume, A. (2013). Advantages of enteral nutrition over parenteral nutrition. Therapeutic Advances in Gastroenterology. 6(2): 157-167.

Silk, D.B., Fairclough, P.D., Clark, M.L., Hegarty, J.E., Marrs, T.C., Addison, J.M., Burston, D., Clegg, K.M. and Mathews, D.M. (1980). Use of peptide rather than free amino acid nitrogen source in chemically defined "elemental" diets. Journal of Parenteral and Enteral Nutrition. 4(6): 548-53.

Weber, E. and Ehrlein, H.J. (1999). Composition of enteral diets and meal providing optimal absorption rates of nutrients in mini pig. American Journal of clinical Nutrition. 69(3): 556-63

Zadak, Z. and Kent- Smith. (2009). L. Basics in clinical nutrition: commercially prepared formulas. The European e-journal of clinical nutrition and Metabolism. 4: 212-215. 